\title{
On Molecular Topological Properties of $\mathrm{TiO}_{2}$ Nanotubes
}

\author{
Nilanjan De \\ Department of Basic Sciences and Humanities (Mathematics), Calcutta Institute of Engineering and Management, Kolkata, India \\ Correspondence should be addressed to Nilanjan De; de.nilanjan@rediffmail.com
}

Received 28 June 2016; Accepted 30 October 2016

Academic Editor: Zhengjun Zhang

Copyright (c) 2016 Nilanjan De. This is an open access article distributed under the Creative Commons Attribution License, which permits unrestricted use, distribution, and reproduction in any medium, provided the original work is properly cited.

Titania nanotube is a well-known semiconductor and has numerous technological applications. In chemical graph theory, topological indices provide an important tool to quantify the molecular structure and it is found that there is a strong correlation between the properties of chemical compounds and their molecular structure. Among different topological indices, degree-based topological indices are most studied and have some important applications. In this study, several old and new degree-based topological indices have been investigated for titania $\mathrm{TiO}_{2}$ nanotubes.

\section{Introduction}

Chemical graph theory is an important branch of mathematical chemistry where we model the chemical phenomenon using graph theory. In chemical graph theory molecules are represented by a molecular graph, which is an unweighted, undirected graph without self-loop or multiple edges such that its vertices correspond to atoms and edges to the bonds between them. A topological index is a numeric quantity which is derived from a molecular graph and it does not depend on labeling or pictorial representation of a graph. It is found that there exist strong connections between the chemical characteristics of chemical compounds and drugs and their topological indices. Topological indices are used for studying quantitative structure-activity relationship (QSAR) and quantitative structure-property relationship (QSPR) for predicting different properties of chemical compounds and biological activities in chemistry, biochemistry, and nanotechnology.

Among different topological indices, degree-based topological indices are most studied and have some important applications in chemical graph theory. The first and second Zagreb indices were first introduced by Gutman and Trinajstić in 1972 [1] and it was reported that these indices are useful in anti-inflammatory activities study of certain chemicals.

Suppose $G$ is a simple connected graph. Let $V(G)$ and $E(G)$, respectively, denote the vertex set and edge set of $G$ and $n$ and $m$, respectively, denote the number of vertices and edges of $G$. Let, for any vertex $v \in V(G), d_{G}(v)$ denote its degree, that is, the number of edges incident with that vertex. Thus, if $N(v)$ denotes the set of vertices which are the neighbors of the vertex $v$, then $|N(v)|=d_{G}(v)$. The first and second Zagreb indices of a graph are denoted by $M_{1}(G)$ and $M_{2}(G)$ and are, respectively, defined as

$$
\begin{aligned}
& M_{1}(G)=\sum_{v \in V(G)} d_{G}(v)^{2}=\sum_{u v \in E(G)}\left[d_{G}(u)+d_{G}(v)\right], \\
& M_{2}(G)=\sum_{u v \in E(G)} d_{G}(u) d_{G}(v) .
\end{aligned}
$$

These indices are one of the oldest and extensively studied topological indices in both mathematical and chemical literature; for details interested readers are referred to [2-7].

The $F$-index of a graph is defined as the sum of cubes of the vertex degrees of the graph which was introduced in 1972, in the same paper where the first and second Zagreb indices were introduced to study the structure-dependency of total $\pi$-electron energy. But this topological index was not further studied till then. Very recently, Furtula and Gutman [8] reinvestigated the index and named it "forgotten topological index" or " $F$-index." Very recently the present authors studied this index for different graph operations [9] and also introduced its coindex version in [10]. In [11] Abdoa 

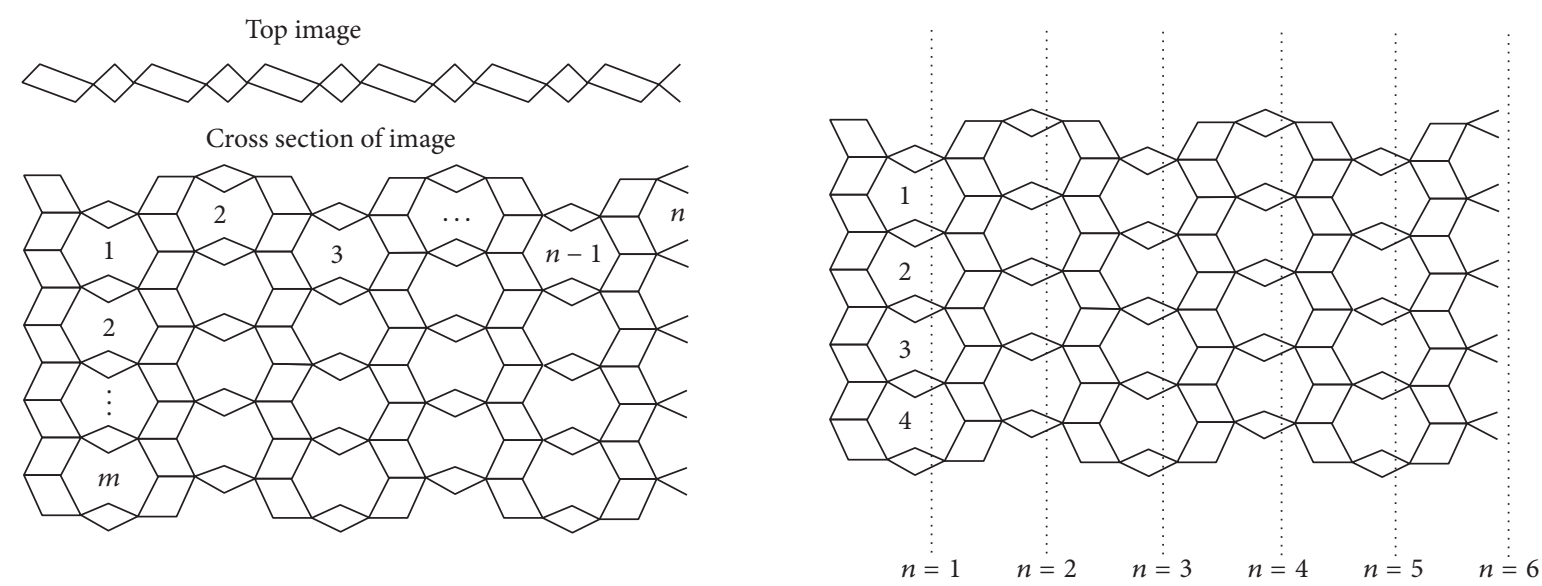

FIgURE 1: The molecular graph of $\mathrm{TiO}_{2}[m, n]$ for $m=4$ and $n=6$.

et al. investigate the trees extremal with respect to the $F$ index. Thus the $F$-index of a graph is defined as

$$
F(G)=\sum_{u v \in E(G)}\left[d_{G}(u)^{2}+d_{G}(v)^{2}\right] .
$$

Albertson in [12] defined another degree-based topological index called irregularity of $G$ as

$$
\operatorname{iir}(G)=\sum_{e=u v \in E(G)}\left|d_{G}(u)-d_{G}(v)\right| .
$$

Tavakoli et al. in [13] found some new results on irregularity of graphs. In [14], De et al. derived irregularity of some composite graphs. Abdo and Dimitrov in [15] determined irregularity of graphs under different graph operations.

Miličević et al. [16] reformulated the Zagreb indices in terms of edge degrees instead of vertex degrees, where the degree of an edge $e=u v$ is defined as $d(e)=d(u)+d(v)-2$, so that the reformulated first and second Zagreb indices of a graph $G$ are defined as

$$
\begin{aligned}
& E M_{1}(G)=\sum_{e \in E(G)} d(e)^{2}, \\
& E M_{2}(G)=\sum_{e \sim f} d(e) d(f) .
\end{aligned}
$$

Here $e \sim f$ means that the edges $e$ and $f$ share a common vertex in $G$; that is, they are adjacent. These reformulated Zagreb indices are subject to large number of chemical and mathematical studies. Different properties of reformulated Zagreb indices have been studied in [17, 18]. In [19], bounds for the reformulated first Zagreb index of graphs with connectivity at most $k$ are obtained. De [20] found some upper and lower bounds of these indices in terms of some other graph invariants and also derived reformulated Zagreb indices of a class of dendrimers [21]. Ji et al. [22, 23] computed these indices for acyclic, unicyclic, bicyclic, and tricyclic graphs. Recently De et al. [24] investigate reformulated first Zagreb index of some graph operations.
Recently, Shirdel et al. [25] introduced a new version of Zagreb index and named as hyper-Zagreb index, which is defined as

$$
H M(G)=\sum_{u v \in E(G)}[d(u)+d(v)]^{2} .
$$

For different recent study of these indices, see [26-28].

During the last two decades, titania nanotubes were systematically synthesized using different methods. Since titania nanotubes are widely used in different applied fields, the study of titania nanotubes has received attention in both chemical and mathematical literature (see [29-31]). Though the study of molecular topological properties of titania nanotubes has been largely limited, we have been attracted to studying molecular topological properties of titania nanotubes. Recently, Malik and Imran [32] studied the Zagreb indices and Nadeem and Shaker [33] studied the eccentric connectivity index of an infinite class of titania nanotubes. In this paper, we study some old and new degreebased topological indices such as $F$-index, reformulated first Zagreb index, third Zagreb index, and hyper-Zagreb index of this type of nanotubes.

\section{Main Results}

The molecular graph of $\mathrm{TiO}_{2}[m, n]$ has total $2 n+2$ rows and $m$ columns and is presented in Figure 1 . For $\mathrm{TiO}_{2}$ nanotubes $2 \leq d(v) \leq 5$, for all $v \in V\left(\mathrm{TiO}_{2}\right)$. We denote the partitions of the vertex set of $\mathrm{TiO}_{2}$ by $V_{i}\left(\mathrm{TiO}_{2}\right)$, where $v \in V\left(\mathrm{TiO}_{2}\right)$ if $d(v)=i$. Thus we have the following partitions of the vertex set:

$$
\begin{aligned}
& V_{2}\left(\mathrm{TiO}_{2}\right)=\left\{v \in V\left(\mathrm{TiO}_{2}\right): d(u)=2\right\}, \\
& V_{3}\left(\mathrm{TiO}_{2}\right)=\left\{v \in V\left(\mathrm{TiO}_{2}\right): d(u)=3\right\}, \\
& V_{4}\left(\mathrm{TiO}_{2}\right)=\left\{v \in V\left(\mathrm{TiO}_{2}\right): d(u)=4\right\}, \\
& V_{5}\left(\mathrm{TiO}_{2}\right)=\left\{v \in V\left(\mathrm{TiO}_{2}\right): d(u)=5\right\} .
\end{aligned}
$$

From direct calculation we get $\left|V_{2}\left(\mathrm{TiO}_{2}\right)\right|=2 m n+4 n$, $\left|V_{3}\left(\mathrm{TiO}_{2}\right)\right|=2 m n,\left|V_{4}\left(\mathrm{TiO}_{2}\right)\right|=2 n$, and $\left|V_{5}\left(\mathrm{TiO}_{2}\right)\right|=2 m n$. 
TABLE 1: The vertex partition of $\mathrm{TiO}_{2}$ nanotubes.

\begin{tabular}{lcccc}
\hline Vertex partition & $V_{2}$ & $V_{3}$ & $V_{4}$ & $V_{5}$ \\
\hline Cardinality & $2 m n+4 n$ & $2 m n$ & $2 n$ & $2 m n$ \\
\hline
\end{tabular}

TABLE 2: The edge partition of $\mathrm{TiO}_{2}$ nanotubes.

\begin{tabular}{lccccc}
\hline $\begin{array}{l}\text { Edge } \\
\text { partition }\end{array}$ & $E_{6}=E_{8}^{*}$ & $E_{7}$ & $E_{8}=E_{15}^{*}$ & $E_{10}^{*}$ & $E_{12}^{*}$ \\
\hline Cardinality & $6 n$ & $4 m n+4 n$ & $6 m n-2 n$ & $4 m n+2 n$ & $2 n$ \\
\hline
\end{tabular}

The partitions of the vertex set of $\mathrm{TiO}_{2}$ nanotubes are given in Table 1.

Again the edge set of $\mathrm{TiO}_{2}$ is divided into three edge partitions based on the sum of degrees of the end vertices and we denote it by $E_{j}\left(\mathrm{TiO}_{2}\right)$ so that if $e=u v \in E_{j}\left(\mathrm{TiO}_{2}\right)$ then $d(u)+d(v)=j$ for $\delta(G) \leq j \leq \Delta(G)$. Thus we write $E\left(\mathrm{TiO}_{2}\right)=\bigcup_{j=\delta}^{\Delta} E_{j}\left(\mathrm{TiO}_{2}\right)$, where

$$
\begin{aligned}
E_{6} & \left(\mathrm{TiO}_{2}\right) \\
= & \left\{e=u v \in E\left(\mathrm{TiO}_{2}\right): d(u)=2, d(v)=4\right\}, \\
E_{7} & \left(\mathrm{TiO}_{2}\right) \\
= & \left\{e=u v \in E\left(\mathrm{TiO}_{2}\right): d(u)=2, d(v)=5\right\} \\
& \cup\left\{e=u v \in E\left(\mathrm{TiO}_{2}\right): d(u)=3, d(v)=4\right\}, \\
E_{8} & \left(\mathrm{TiO}_{2}\right) \\
= & \left\{e=u v \in E\left(\mathrm{TiO}_{2}\right): d(u)=3, d(v)=5\right\} .
\end{aligned}
$$

Similarly, from direct calculation we get $\left|E_{6}\left(\mathrm{TiO}_{2}\right)\right|=$ 6n, $\left|E_{2}\left(\mathrm{TiO}_{2}\right)\right|=4 m n+4 n$, and $\left|E_{8}\left(\mathrm{TiO}_{2}\right)\right|=6 m n-2 n$.

Similarly, the edge set of $\mathrm{TiO}_{2}$ is also divided into four edge partitions based on the product of degrees of the end vertices and we denote it by $E_{k}^{*}\left(\mathrm{TiO}_{2}\right)$ so that if $e=u v \in$ $E_{k}^{*}\left(\mathrm{TiO}_{2}\right)$ then $d(u) d(v)=k$ for $\delta(G)^{2} \leq k \leq \Delta(G)^{2}$. Thus we have the following partitions of the edge set:

$$
\begin{aligned}
& E_{8}^{*}\left(\mathrm{TiO}_{2}\right) \\
& \quad=\left\{e=u v \in E\left(\mathrm{TiO}_{2}\right): d(u)=2, d(v)=4\right\}, \\
& E_{10}^{*}\left(\mathrm{TiO}_{2}\right) \\
& \quad=\left\{e=u v \in E\left(\mathrm{TiO}_{2}\right): d(u)=2, d(v)=5\right\}, \\
& E_{12}^{*}\left(\mathrm{TiO}_{2}\right) \\
& \quad=\left\{e=u v \in E\left(\mathrm{TiO}_{2}\right): d(u)=3, d(v)=4\right\}, \\
& E_{15}^{*}\left(\mathrm{TiO}_{2}\right) \\
& \quad=\left\{e=u v \in E\left(\mathrm{TiO}_{2}\right): d(u)=3, d(v)=5\right\} .
\end{aligned}
$$

In this case, from direct calculation we get $\left|E_{8}^{*}\left(\mathrm{TiO}_{2}\right)\right|=$ $6 n,\left|E_{10}^{*}\left(\mathrm{TiO}_{2}\right)\right|=4 m n+2 n,\left|E_{12}^{*}\left(\mathrm{TiO}_{2}\right)\right|=2 n$, and $\left|E_{15}^{*}\left(\mathrm{TiO}_{2}\right)\right|=6 m n-2 n$. Clearly, $E_{7}=E_{10}^{*} \cup E_{12}^{*}, E_{6}=E_{8}^{*}$, $E_{8}=E_{15}^{*}$. The partitions of the edge set of $\mathrm{TiO}_{2}$ nanotubes are given in Table 2.
In the following we calculate the $F$-index, first reformulated Zagreb index, irregularity, and hyper-Zagreb index of the $\mathrm{TiO}_{2}[m, n]$ nanotube as defined in the previous section.

Theorem 1. The F-index of $\mathrm{TiO}_{2}[m, n]$ nanotube is given by

$$
F\left(\mathrm{TiO}_{2}\right)=320 m n+160 n \text {. }
$$

Proof. From (2) and by cardinalities of the vertex partitions of $\mathrm{TiO}_{2}$ nanotube, we have

$$
\begin{aligned}
F\left(\mathrm{TiO}_{2}\right)= & \sum_{v \in V\left(\mathrm{TiO}_{2}\right)} d(v)^{3} \\
= & \sum_{v \in V_{2}} d(v)^{3}+\sum_{v \in V_{3}} d(v)^{3}+\sum_{v \in V_{4}} d(v)^{3} \\
& +\sum_{v \in V_{5}} d(v)^{3} \\
= & 8\left|V_{2}\right|+27\left|V_{3}\right|+64\left|V_{4}\right|+125\left|V_{5}\right| \\
= & 8(2 m n+4 n)+27(2 m n)+64(2 n) \\
& +125(2 m n)
\end{aligned}
$$

from where the desired result follows.

Theorem 2. The third Zagreb index or irregularity of $\mathrm{TiO}_{2}[m, n]$ nanotube is given by

$$
\operatorname{irr}\left(\mathrm{TiO}_{2}\right)=316 m n+124 n .
$$

Proof. From (3) and by cardinalities of the edge partitions of $\mathrm{TiO}_{2}$ nanotube, we have

$$
\begin{aligned}
\operatorname{irr}\left(\mathrm{TiO}_{2}\right)= & \sum_{u v \in E\left(\mathrm{TiO}_{2}\right)}|d(u)-d(v)| \\
= & \sum_{u v \in E_{8}^{*}}|d(v)-d(v)|+\sum_{u v \in E_{10}^{*}}|d(v)-d(v)| \\
& +\sum_{u v \in E_{12}^{*}}|d(v)-d(v)| \\
& +\sum_{u v \in E_{15}^{*}}|d(v)-d(v)| \\
= & 2\left|E_{8}^{*}\right|+3\left|E_{10}^{*}\right|+\left|E_{12}^{*}\right|+2\left|E_{15}^{*}\right| \\
= & 2(6 n)+3(4 m n+2 n)+2 n \\
& +2(6 m n-2 n)
\end{aligned}
$$

from where the desired result follows.

Theorem 3. The reformulated first Zagreb index of $\mathrm{TiO}_{2}[m, n]$ nanotube is given by

$$
E M_{1}\left(\mathrm{TiO}_{2}\right)=316 m n+124 n .
$$


Proof. From (4) and by cardinalities of the edge partitions of $\mathrm{TiO}_{2}$ nanotube, we have

$$
\begin{aligned}
E M_{1}\left(\mathrm{TiO}_{2}\right)= & \sum_{u v \in E\left(\mathrm{TiO}_{2}\right)}[d(v)+d(v)-2]^{2} \\
= & \sum_{u v \in E_{6}}[d(v)+d(v)-2]^{2} \\
& +\sum_{u v \in E_{7}}[d(v)+d(v)-2]^{2} \\
& +\sum_{u v \in E_{8}}[d(v)+d(v)-2]^{2} \\
= & 16\left|E_{6}\right|+25\left|E_{7}\right|+36\left|E_{8}\right| \\
= & 16(6 n)+25(4 m n+4 n) \\
& +36(6 m n-2 n)
\end{aligned}
$$

from where the desired result follows.

Theorem 4. The hyper-Zagreb index of $\mathrm{TiO}_{2}[m, n]$ nanotube is given by

$$
H M\left(\mathrm{TiO}_{2}\right)=580 m n+284 n .
$$

Proof. From (6) and by cardinalities of the edge partitions of $\mathrm{TiO}_{2}$ nanotube, we have

$$
\begin{aligned}
H M\left(\mathrm{TiO}_{2}\right)= & \sum_{u v \in E\left(\mathrm{TiO}_{2}\right)}[d(v)+d(v)]^{2} \\
= & \sum_{u v \in E_{6}}[d(v)+d(v)]^{2} \\
& +\sum_{u v \in E_{7}}[d(v)+d(v)]^{2} \\
& +\sum_{u v \in E_{8}}[d(v)+d(v)]^{2} \\
= & 36\left|E_{6}\right|+49\left|E_{7}\right|+64\left|E_{8}\right| \\
= & 36(6 n)+49(4 m n+4 n) \\
& +64(6 m n-2 n)
\end{aligned}
$$

from where the desired result follows.

\section{Conclusion}

In this paper, the expressions for some old and new degreebased topological indices such as F-index, reformulated first Zagreb index, third Zagreb index, and hyper-Zagreb index of titania $\mathrm{TiO}_{2}$ nanotubes have been derived. These explicit formulae can correlate the chemical structure of titania nanotubes to information about their physical structure.

\section{Competing Interests}

The author declares no conflict of interests.

\section{References}

[1] I. Gutman and N. Trinajstić, "Graph theory and molecular orbitals. Total $\varphi$-electron energy of alternant hydrocarbons," Chemical Physics Letters, vol. 17, no. 4, pp. 535-538, 1972.

[2] G. H. Fath-Tabar, "Old and new Zagreb indices of graphs," MATCH Communications in Mathematical and in Computer Chemistry, vol. 65, no. 1, pp. 79-84, 2011.

[3] M. H. Khalifeh, H. Yousefi-Azari, and A. R. Ashrafi, "The first and second Zagreb indices of some graph operations," Discrete Applied Mathematics, vol. 157, no. 4, pp. 804-811, 2009.

[4] B. Zhou, "Upper bounds for the Zagreb indices and the spectral radius of series-parallel graphs," International Journal of Quantum Chemistry, vol. 107, no. 4, pp. 875-878, 2007.

[5] B. Zhou and I. Gutman, "Further properties of Zagreb indices," MATCH Communications in Mathematical and in Computer Chemistry, vol. 54, no. 1, pp. 233-239, 2005.

[6] K. Xu, K. Tang, H. Liu, and J. Wang, "The Zagreb indices of bipartite graphs with more edges," Journal of Applied Mathematics \& Informatics, vol. 33, no. 3-4, pp. 365-377, 2015.

[7] K. C. Das, K. Xu, and J. Nam, "Zagreb indices of graphs," Frontiers of Mathematics in China, vol. 10, no. 3, pp. 567-582, 2015.

[8] B. Furtula and I. Gutman, "A forgotten topological index," Journal of Mathematical Chemistry, vol. 53, no. 4, pp. 1184-1190, 2015.

[9] N. De, S. M. A. Nayeem, and A. Pal, "F-index of some graph operations," Discrete Mathematics, Algorithms and Applications, vol. 8, no. 2, Article ID 1650025, 17 pages, 2016.

[10] N. De, S. M. A. Nayeem, and A. Pal, "The F-coindex of some graph operations," SpringerPlus, vol. 5, article 221, 2016.

[11] H. Abdoa, D. Dimitrov, and I. Gutman, "On extremal trees with respect to the F-index," https://arxiv.org/abs/1509.03574.

[12] M. O. Albertson, “The irregularity of a graph," Ars Combinatoria, vol. 46, pp. 219-225, 1997.

[13] M. Tavakoli, F. Rahbarnia, and A. R. Ashrafi, "Some new results on irregularity of graphs," Journal of Applied Mathematics \& Informatics, vol. 32, no. 5-6, pp. 675-685, 2014.

[14] N. De, A. Pal, and S. M. A. Nayeem, "The irregularity of some composite graphs," International Journal of Applied and Computational Mathematics, vol. 2, no. 3, pp. 411-420, 2016.

[15] H. Abdo and D. Dimitrov, "The irregularity of graphs under graph operations," Discussiones Mathematicae Graph Theory, vol. 34, no. 2, pp. 263-278, 2014.

[16] A. Miličević, S. Nikolić, and N. Trinajstić, "On reformulated Zagreb indices," Molecular Diversity, vol. 8, no. 4, pp. 393-399, 2004.

[17] B. Zhou and N. Trinajstić, "Some properties of the reformulated Zagreb indices," Journal of Mathematical Chemistry, vol. 48, no. 3, pp. 714-719, 2010.

[18] A. Ilić and B. Zhou, “On reformulated Zagreb indices," Discrete Applied Mathematics, vol. 160, no. 3, pp. 204-209, 2012.

[19] G. Su, L. Xiong, L. Xu, and B. Ma, "On the maximum and minimum first reformulated Zagreb index of graphs with connectivity at most k," Filomat, vol. 25, no. 4, pp. 75-83, 2011.

[20] N. De, "Some bounds of reformulated Zagreb indices," Applied Mathematical Sciences, vol. 6, no. 101, pp. 5005-5012, 2012.

[21] N. De, "Reformulated Zagreb indices of dendrimers," Mathematica Aeterna, vol. 3, no. 2, pp. 133-138, 2013. 
[22] S. Ji, X. Li, and B. Huo, "On reformulated Zagreb indices with respect to acyclic, unicyclic and bicyclic graphs," MATCH Communications in Mathematical and in Computer Chemistry, vol. 72, no. 3, pp. 723-732, 2014.

[23] S. Ji, X. Li, and Y. Qu, "On reformulated zagreb indices with respect to tricyclic graphs," https://arxiv.org/abs/1406.7169.

[24] N. De, S. M. A. Nayeem, and A. Pal, "Reformulated first Zagreb index of some graph operations," Mathematics, vol. 3, no. 4, pp. 945-960, 2015.

[25] G. H. Shirdel, H. Rezapour, and A. M. Sayadi, "The hyper Zagreb index of graph operations," Iranian Journal of Mathematical Chemistry, vol. 4, no. 2, pp. 213-220, 2013.

[26] M. Veylaki, M. J. Nikmehr, and H. A. Tavallaee, "The third and hyper-Zagreb coindices of some graph operations," Journal of Applied Mathematics and Computing, vol. 50, no. 1-2, pp. 315325, 2016.

[27] B. Basavanagoud and S. Patil, "A note on Hyper-Zagreb index of graph operations," Iranian Journal of Mathematical Chemistry, vol. 7, no. 1, p. 8992, 2016.

[28] M. R. Farahani, "Computing the hyper-Zagreb index of hexagonal nanotubes," Journal of Chemistry and Materials Research, vol. 2, no. 1, pp. 16-18, 2015.

[29] R. A. Evarestov, Y. F. Zhukovskii, A. V. Bandura, and S. Piskunov, "Symmetry and models of single-walled $\mathrm{TiO}_{2}$ nanotubes with rectangular morphology," Central European Journal of Physics, vol. 9, no. 2, pp. 492-501, 2011.

[30] V. V. Ivanovskaya, A. N. Enyashin, and A. L. Ivanovskiǔ, "Nanotubes and fullerene-like molecules based on $\mathrm{TiO}_{2}$ and $\mathrm{ZrS}_{2}$ : electronic structure and chemical bond," Russian Journal of Inorganic Chemistry, vol. 49, no. 2, pp. 244-251, 2004.

[31] A. N. Enyashin and G. Seifert, "Structure, stability and electronic properties of $\mathrm{TiO}_{2}$ nanostructures," Physica Status Solidi, vol. 242, no. 7, pp. 1361-1370, 2005.

[32] M. A. Malik and M. Imran, "On multiple Zagreb index of $\mathrm{TiO}_{2}$ nanotubes," Acta Chimica Slovenica, vol. 62, no. 4, pp. 973-976, 2015.

[33] I. Nadeem and H. Shaker, "On eccentric connectivity index of $\mathrm{TiO}_{2}$ nanotubes," Acta Chimica Slovenica, vol. 63, pp. 363-368, 2016. 

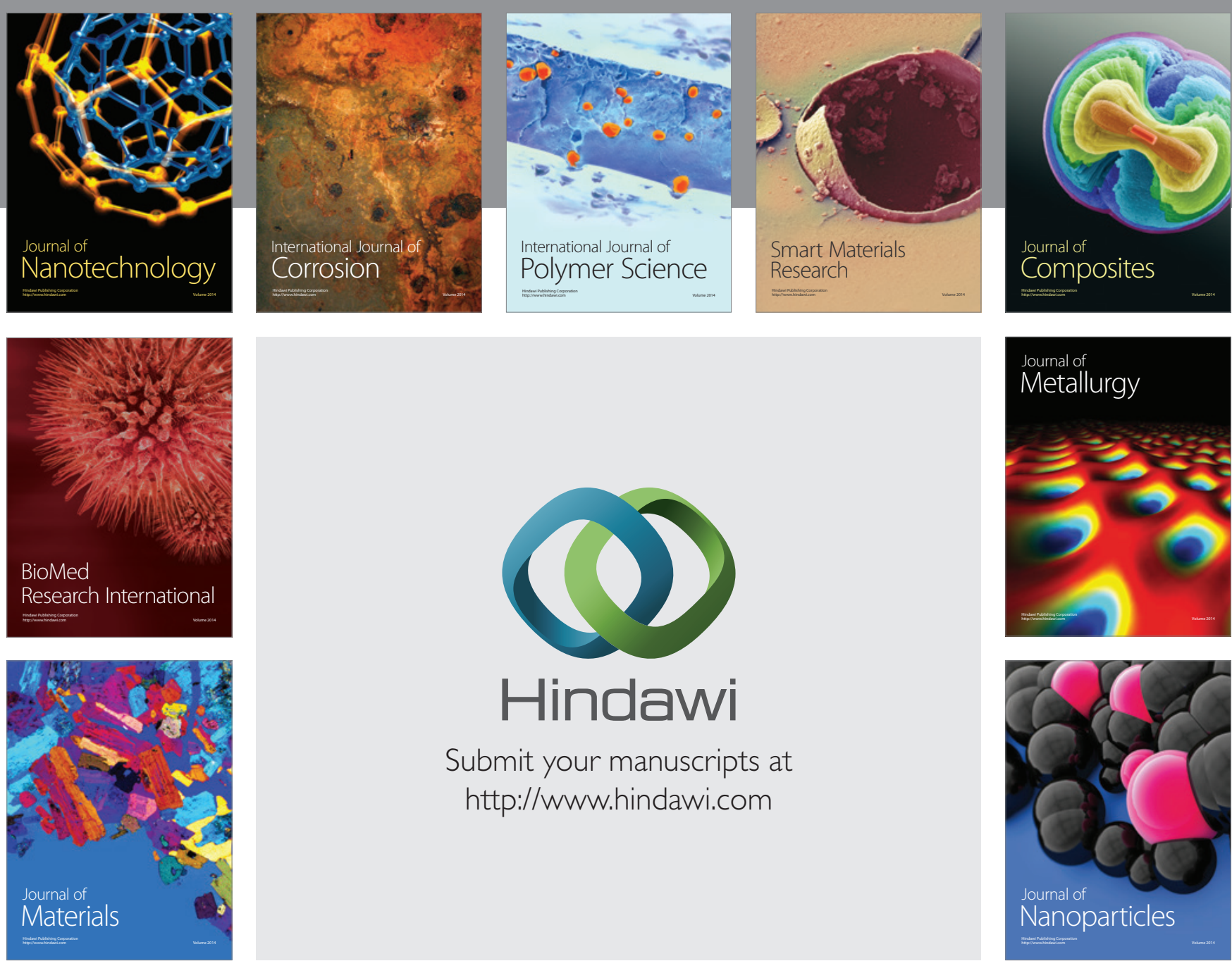

\section{Hindawi}

Submit your manuscripts at

http://www.hindawi.com

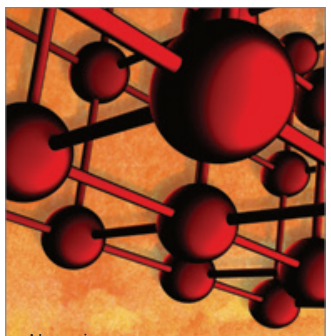

Materials Science and Engineering
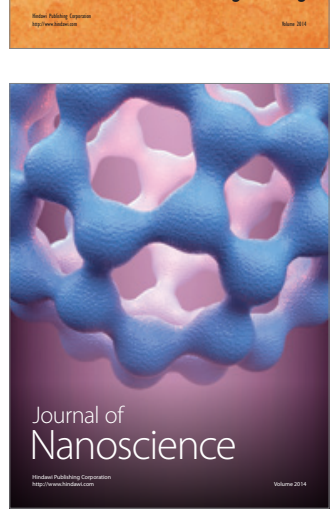
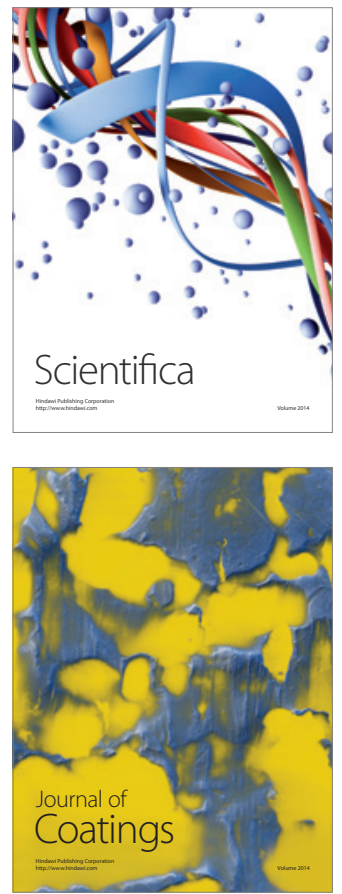
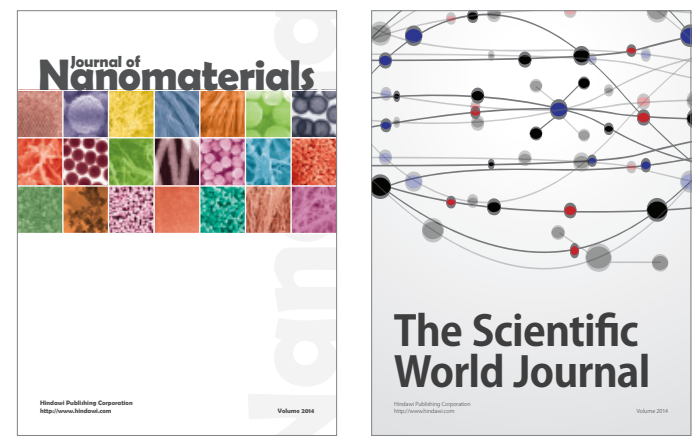

The Scientific World Journal
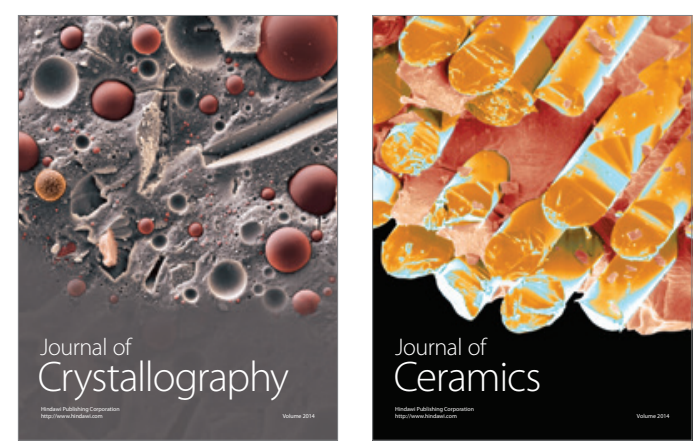
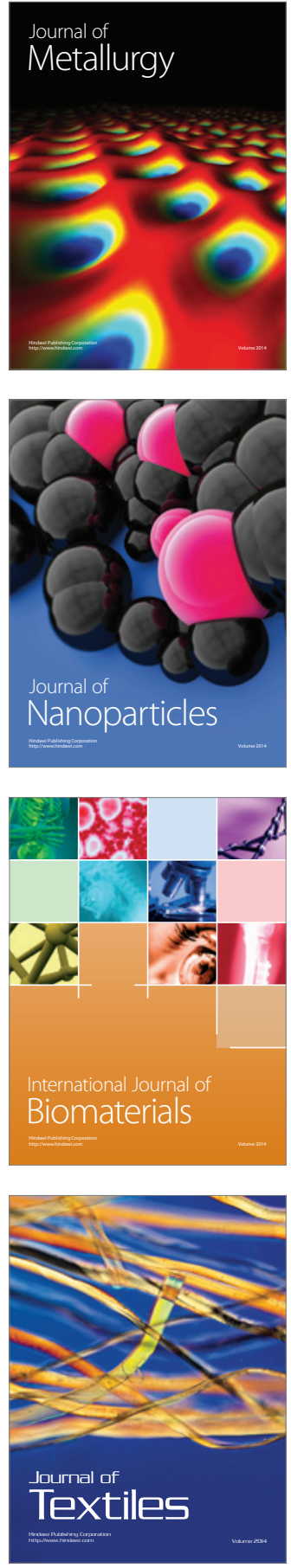